\title{
Microbiology Susceptibility External File Path
}

National Cancer Institute

\section{Source}

National Cancer Institute. Microbiology Susceptibility External File Path. NCI Thesaurus.

Code C162149.

The literal identifier of a microbiology susceptibility external file name. 